\title{
LA RENOVACIÓN DE LOS CUADROS POLÍTICOS LOCALES EN EL PRIMER FRANQUISMO: EL PAPEL DEL TERCIO SINDICAL
}

\author{
THE RENOVATION OF THE LOCAL POLITICAL POSITIONS \\ IN THE FIRST FRANCOISM: THE ROLE OF THE THIRD UNION
}

Antonio Pérez Enbeita*

Universidad del País Vasco/Euskal Herriko Unibertsitatea, Bilbao, España

\begin{abstract}
RESUMEN: El propósito de este artículo es plantear la hipótesis del uso por parte de la dictadura franquista de las elecciones locales y concretamente del tercio sindical para renovar los cuadros políticos locales. Se introdujeron así en las instituciones personas de un perfil diferente al que hasta ese momento había monopolizado dichos cargos. Para ello se ha realizado un estudio de caso en la ciudad de Bilbao, en la que la élite económica local controlaba el Ayuntamiento y monopolizaba los puestos en el mismo, y en la que la implantación del sistema de tercios implicó un cambio en el perfil socio económico de buena parte de los ediles elegidos por el tercio sindical. La característica clave de esta nueva generación de políticos fue la lealtad absoluta a la dictadura, al haber desarrollado toda su carrera política cuando esta estaba ya implantada.
\end{abstract}

PALABRAS CLAVE: Primer franquismo, poder local, ayuntamiento, prosopografía, tercio sindical.

ABSTRACT: The porpose of this article is to propose the hypothesis of the use by the francoist dictatorship of the local elections and specifically of the union third to renovate the local political positions. By this way they were introduced people of a different profile than the ones that that had monopolized those positions. For it, a case study has been carried out in the city of Bilbao, where the local economic elite controlled the Town Hall and monopolized the positions in it, and where the implantation of the thirds system involved a change in the socioeconomic profile of a part of the councilors chosen by the syndical third. The key characteristic of that new generation of politicians was the absolute loyalty to the dictatorship, because they had developed their entire career when the dictatorship was already implemented.

KEYWORDS: First francoism, local power, Town Hall, prosopography, syndical third.

* Correspondencia a / Corresponding author: Antonio Pérez Enbeita. UPV/EHU-Gogora. María Díaz Haroko kalea, 3-3. ${ }^{\mathrm{a}}$ planta (48013 Bilbao). - aembeita91@gmail.com - https://orcid.org/0000-0001-6940-7421

Cómo citar / How to cite: Pérez Enbeita, Antonio (2021). "La renovación de los cuadros políticos locales en el primer franquismo: el papel del tercio sindical», Historia Contemporánea, 67, 897-921. (https://doi.org/10.1387/hc.21271).

Recibido/Received: 2019-12-03; Aceptado/Accepted: 2020-01-20.

ISSN 1130-2402 - eISSN 2340-0277 / (C) 2021 Historia Contemporánea (UPV/EHU)

cc) (i) $\odot$ Esta obra está bajo una Licencia

(c) Creative Commons Atribución-NoComercial-SinDerivadas 4.0 Internacional 
El objetivo del presente artículo es el análisis del poder local en el primer franquismo ${ }^{1}$. Para ello, a partir de un estudio de caso, planteamos la hipótesis de que la dictadura aprovechó el sistema electoral instaurado a través de la Ley de Bases de Régimen Local de 1945 para, entre otras cuestiones, introducir en los Ayuntamientos a personas ajenas a las élites que hasta ese momento habían monopolizado dichos cargos. Hemos analizado los cambios en el perfil social, económico, cultural y político de los miembros de las corporaciones municipales bilbaínas durante el primer franquismo y hemos puesto en evidencia el cambio que se produjo tras la creación del sistema de tercios. Los tercios familiar, sindical y de entidades formaron parte, de cara al exterior, de una operación cosmética llevada a cabo por la dictadura con el fin de trasladar al una imagen presentable ante las potencias occidentales tras la derrota del Eje en la Segunda Guerra Mundial, al quedar en entredicho la posición internacional de la España de Franco. No obstante, a través del tercio sindical, entraron a formar parte del Ayuntamiento de Bilbao una serie de personas de un perfil diferente a las que hasta entonces habían ocupado los cargos políticos locales en la capital vizcaína. Por lo tanto, consideramos que este sistema sirvió también para renovar los cuadros políticos locales franquistas impulsando un perfil distinto al que venía siendo habitual. Esta hipótesis deberá ser confirmada mediante el estudio de otras corporaciones del mismo periodo.

Abundan los estudios dedicados a analizar el poder local en el franquismo a lo largo y ancho de toda la geografía española, como pueden ser los casos de Palencia ${ }^{2}$, Cantabria $^{3}$, Marbella $^{4}$, Barcelona $^{5}$, Bilbao $^{6}$, San Sebastián ${ }^{7}$, Pamplona ${ }^{8}$, Vitoria ${ }^{9}$, Alicante ${ }^{10}$, Murcia $^{11}$ o Extremadu-

${ }^{1}$ Sobre el poder local en el franquismo a nivel general existen innumerables estudios, por poner tan solo algunos ejemplos: Nicolás Marín, 1999; Canales Serrano, 2006; Rodríguez Barreira, 2013; Hernández Burgos, 2015, Presas Sobrado, 2016; Ponce Alberca, 2016; Domper Lasús, 2018.

2 García Ramos, 2003.

3 Sanz Hoya, 2008.

4 Rubia Osorio, 2017.

5 Marín Corbera, 2000; Marín Corbera, Risques, Tébar y Casanellas, 2015.

6 Agirreazkuenaga y Urquijo Goitia, 2008.

7 Aizpuru Murua, 2010.

${ }^{8}$ Larraza Micheltorena, 2003; Larraza Micheltorena, 2012.

9 López de Maturana, 2014.

10 Sanz Alberola, 1999.

11 Nicolás Marín, 1982. 
$\mathrm{ra}^{12}$, por poner algunos ejemplos de trabajos en este ámbito ${ }^{13}$. Estos trabajos han supuesto una herramienta clave a la hora de desarrollar un exhaustivo análisis de las lógicas del poder local en la dictadura franquista, si bien queda todavía mucho camino por recorrer. Se han estudiado desde las instituciones municipales a la vida cotidiana de los habitantes en una etapa determinada, desde la implantación del régimen durante los primeros años hasta el surgimiento y desarrollo de diferentes vías de resistencia antifranquista. Partiendo de lo pequeño podremos comprender mejor el franquismo en toda su complejidad, entendiendo cómo la dictadura se impuso a nivel local y cómo los cuadros dirigentes fueron renovándose a lo largo de los años.

Hasta la entrada en vigor de la Ley de Bases de Régimen Local de 1945, el consistorio bilbaíno había sido un coto cerrado, con algunas excepciones explicadas debido a los méritos individuales de personas concretas, reservado para los miembros de la alta burguesía vasca que había apoyado el fallido golpe de Estado de Franco desde el primer momento ${ }^{14}$. Esa élite local que controlaba los medios de producción de la zona recibió después su recompensa por parte de la dictadura en forma de cargos políticos en el organigrama franquista, lo que en el caso bilbaíno se traduce en el acaparamiento de la mayoría de cargos políticos en la zona ${ }^{15}$. No obstante, a partir de la celebración de las primeras elecciones locales de la dictadura, el perfil de los políticos bilbaínos se vio alterado por la entrada en el consistorio de una serie de hombres que no pertenecían a esa élite local.

Los ediles elegidos por el tercio sindical responden en su mayoría a unas características socio económicas diferentes a las que hasta ese momento habían sido la norma en el Ayuntamiento, aunque ello no supuso un cambio en el funcionamiento de la institución. La llegada a la política de estas personas coincide con un cambio generacional algo más de una

12 Aguado Benítez, 2010.

13 Existen muchos otros trabajos sobre esta cuestión, verbigracia: Aizpuru Murua, 2017; Alcalde, 2010; Arco Blanco, 2005; Arrieta, 2003; Barruso Barés, 2000, pp. 255350; Barruso Barés, 2005; Canales Serrano, 2006; Cabrero, 2006; Cenarro Lagunas, 1997; Clara, 1987; Cobo Romero, 1994; González Cortes; Molinero, 2009.

${ }^{14}$ Los datos sobre los políticos del Ayuntamiento de Bilbao que manejamos en este artículo tiene su origen en Pérez Embeita, El poder local en el primer franquismo. Análisis prosopográfico de los miembros del Ayuntamiento de Bilbao y su gestión político-administrativa (1937-1959), UPV/EHU, 2019.

15 Además del Ayuntamiento, también la Diputación de Vizcaya estuvo en manos de este grupo de hombres que formaban la élite local. Sobre esta cuestión, ver: Agirreazkuenaga y Alonso Olea, 2014, pp. 526-540. 
década después de la constitución del primer Ayuntamiento franquista en Bilbao. Este grupo de concejales elegidos a través del tercio sindical provenía de los engranajes del partido único, no pertenecía a las tradiciones políticas que habían apoyado al franquismo desde el fallido golpe de Estado y había realizado toda su carrera política bajo el paraguas de la dictadura debido en muchos casos a su juventud, con lo que su ideología y su lealtad eran exclusivamente franquistas.

Como vamos a comprobar, hasta la celebración de las elecciones, el Ayuntamiento de Bilbao estuvo ocupado prácticamente en exclusividad por personas con unas características socio económicas privilegiadas, que los sitúan como parte de una élite que controló las instituciones locales así como los medios de producción de la zona, monopolizando el poder político y económico durante la dictadura. Sin embargo, el cambio de sistema a la hora de escoger a las personas que ocuparían estos cargos permitió la entrada de un perfil diferente con unas características que diferían no solo en el ámbito socio económico sino también en la trayectoria política.

\section{El perfil de los ediles bilbaínos durante el primer franquismo}

Bilbao fue conquistado por los franquistas en junio de 1937, y ese mismo mes se constituyó el primero de los Ayuntamientos que gobernaron la ciudad durante la dictadura. Las primeras corporaciones municipales fueron provisionales y estuvieron compuestas por un número reducido de hombres, hasta que la estabilidad alcanzada por el régimen franquista permitió la consolidación de las instituciones de la dictadura y la normalización de su funcionamiento y composición. En este caso, la llegada a la alcaldía de Joaquín Zuazagoitia en 1942 supuso un punto de inflexión y otorgó estabilidad a la institución, convirtiéndose en el alcalde más longevo de la historia reciente de Bilbao. Zuazagoitia dejó el cargo en 1959, momento que delimita el marco cronológico que hemos utilizado. Las primeras elecciones locales se celebraron en 1948, y a partir de entonces se llevaron a cabo renovaciones de la mitad de las corporaciones municipales cada tres años ${ }^{16}$.

${ }^{16}$ Los alcaldes de Bilbao en este periodo fueron: Jose María Areilza (1937-1938); José María González de Careaga (1938-1938); José Félix de Lequerica (1938-1939); José María Oriol Urquijo (1939-1941); Tomás Pero-Sanz (1941-1942) y Joaquín Zuazagoitia (1942-1959). 
Tras un largo proceso de investigación utilizando la prosopografía como herramienta para analizar al personal político del Ayuntamiento de Bilbao llegamos a la conclusión de que esta institución estuvo dominada por un grupo reducido de hombres que formaban parte de la élite local que manejó los hilos del poder en la provincia y que poseía también los medios de producción que le permitían controlar el ámbito económico. Este grupo estaba formado por algunas de las más importantes familias de la burguesía industrial vizcaína ${ }^{17}$, y de hecho es habitual encontrar sagas y otras vinculaciones familiares entre los miembros del consistorio bilbaíno, así como nexos entre los ediles y algunas de las empresas más importantes del período, caso de los Bancos de Bilbao y de Vizcaya ${ }^{18}$.

Esta élite local controló las instituciones de la zona, organismos en los que mantuvo los puestos de mayor responsabilidad, como la alcaldía y las tenencias de alcaldía en el caso de la capital vizcaína. Un ejemplo claro lo encontramos ya en el primer consistorio franquista de Bilbao. La primera comisión gestora de la ciudad estuvo presidida por José María Areilza, miembro de una de las más poderosas familias de la burguesía local y con una carrera política previa a la dictadura en el seno de la ultraderecha, mismo caso que Esteban Calle Iturrino, periodista bilbaíno que había formado parte del Ayuntamiento entre 1934 y 1935. Por otro lado, José María Careaga era también miembro de una familia de abolengo en la zona y posteriormente sería alcalde de Bilbao, y Manuel María Arredondo fue escogido debido principalmente a su pertenencia al tradicionalismo, una fuerza política con raigambre en toda la zona y cuyos miembros tuvieron siempre representación en el consistorio. Así, los dos ediles de mayor peso del Ayuntamiento, que después tuvieron cargos de mayor importancia en el organigrama franquista, fueron los dos pertenecientes a las familias de la burguesía industrial vasca que habían apoyado al dictador desde el primer momento, y que después fueron recompensadas por ello.

17 Ver Urquijo Goitia, 2019, pp. 255-279.

18 Entre 1937 y 1959 hubo al menos quince familias emparentadas entre sí por medio del matrimonio, a lo que hay que sumar las sagas familiares de padres e hijos y de hermanos que estuvieron en el consistorio en diferentes etapas. Estas familias eran parte de esa burguesía industrial de la que venimos hablando, de la que formaban parte conocidos apellidos como los Ibarra, los Oriol, los Careaga o los Churruca; se relacionaban y formaban parte de las mismas asociaciones e incluso empresas, y en muchos casos se casaban entre ellos, vinculando así algunas de las familias más poderosas y ampliando el imperio empresarial de las mismas. 
Esta situación se mantuvo con la consolidación de la dictadura y la normalización del funcionamiento interno de las instituciones, es decir, cuando los Ayuntamientos se estabilizaron y el número de miembros que formaban las comisiones gestoras aumentó hasta tener un tamaño habitual en una ciudad densamente poblada como Bilbao. A partir de 1939 las corporaciones municipales aumentaron considerablemente el número de personas que las componían, aunque la gran mayoría continuaron siendo parte de la élite local en mayor o menor medida. Algunos casos excepcionales los encontramos en la inclusión de hombres de una extracción social más baja pero que habían tenido una destacada actuación en la guerra civil o que habían pertenecido a Falange desde su fundación, méritos recompensados con un puesto de concejal, aunque no en el cuadro dirigente del Ayuntamiento. Una de las características comunes en los consistorios del franquismo era el equilibrio que Franco impuso entre las diferentes fuerzas políticas que lo habían apoyado y que después habían quedado diluidas en el partido único, lo que en el caso bilbaíno se traduce en la inclusión de miembros de Falange que no pertenecían a las élites locales, cercanas al tradicionalismo y al monarquismo de ultraderecha, como se puede comprobar en la siguiente tabla:

\section{Tabla 1}

Adscripción ideológica de los miembros del Ayuntamiento de Bilbao. 1937-1959

\begin{tabular}{|c|c|c|c|c|}
\hline Filiación política & Alcaldes & $\begin{array}{c}\text { Tenientes que } \\
\text { presidieron comisiones }\end{array}$ & Concejales & $\begin{array}{l}\text { Datos } \\
\text { generales }\end{array}$ \\
\hline Renovación Española & $50 \%$ & $12 \%$ & $15 \%$ & $17 \%$ \\
\hline Comunión Tradicionalista & $33 \%$ & $20 \%$ & $22 \%$ & $22 \%$ \\
\hline Falange & - & $20 \%$ & $25 \%$ & $22 \%$ \\
\hline Movimiento Nacional ${ }^{19}$ & - & $34 \%$ & $31 \%$ & $30 \%$ \\
\hline Otros & $17 \%$ & $14 \%$ & $7 \%$ & $9 \%$ \\
\hline
\end{tabular}

Fuente: elaboración propia ${ }^{20}$.

${ }^{19}$ Hemos denominado a este grupo Movimiento Nacional, utilizando esta nomenclatura para referirnos a los ediles que no procedían de ninguna tradición ideológica concreta y que medraron políticamente durante el franquismo. No hay que confundir el uso que aquí damos al Movimiento con un sinónimo de FET-JONS.

${ }^{20}$ Los gráficos y tablas que aparecen a lo largo en esta investigación han sido de elaboración propia, a menos que se indique lo contrario. Para ello, se han utilizado múlti- 


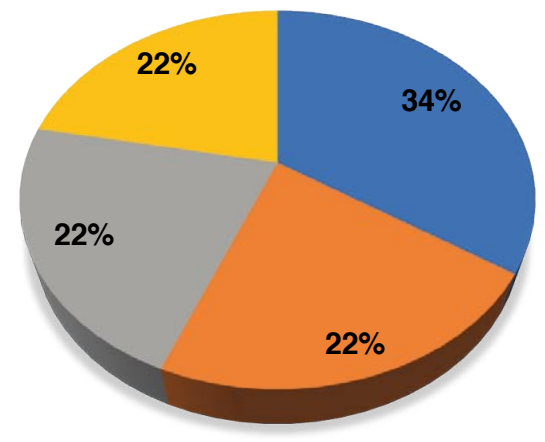

-Empresario $\backsim$ Abogado $\backsim$ Profesional liberal $₫$ Trabajador por cuenta ajena

Fuente: elaboración propia.

\section{Gráfico 1}

Perfil laboral de los miembros del Ayuntamiento de Bilbao, 1937-1959

No obstante, los puestos de mayor responsabilidad en el Ayuntamiento estuvieron siempre ocupados por miembros de esa élite local, que ocupaban la alcaldía y las tenencias de alcaldía, frente a un grupo de concejales «rasos», cuya presencia era meramente testimonial en muchos casos. Para comprobar esto se ha realizado un análisis prosopográfico comparativo entre los alcaldes y tenientes frente al resto de conceja-

ples fuentes documentales en cada uno de ellos. Debido a esto, haremos a continuación un compendio de las fuentes utilizadas, que serán las mismas en todos los gráficos. Los gráficos han sido elaborados sobre la información obtenida de: los índices de Padrón del ayuntamiento de Bilbao de los años 1910, 1920, 1930, 1940 y 1945; los Nomenclátores Municipales de los años 1942, 1953, 1955, 1958, 1961 y 1972; las Memorias Municipales de los años 1937-1939, 1948-1953, 1954-1958 y 1959-1964; las Actas del pleno del Ayuntamiento de Bilbao entre 1937 y 1959; el Archivo General de la Administración; el Archivo Histórico de la Diputación Foral de Bizkaia; el Archivo Municipal de Bilbao; el Archivo Histórico Eclesiástico de Bizkaia; el Archivo Histórico de la Diócesis de Vitoria; el Registro Civil de Irun; el Archivo Eclesiástico del Ministerio de Defensa; el Archivo Municipal de Ataún; el Archivo del BBVA; el Archivo Municipal de Soto en Cameros; el libro de Agirreazkuenaga y Urquijo Goitia (dirs.), Bilbao desde sus alcaldes..., vol. III; los periódicos ABC, La Gaceta del Norte y El Correo Español-El Pueblo Vasco; el Boletín Oficial del Estado (BOE); la enciclopedia online Auñamendi y Los Libros de Sociedades del Registro Mercantil de Bizkaia. 
les ${ }^{21}$, análisis que confirma que las características socio-económicas de los primeros son netamente superiores a las de sus colegas en el Ayuntamiento. Destacan especialmente las diferencias en el ámbito de los estudios superiores y en la dedicación profesional de los ediles, pero también en el origen hallamos significativas divergencias, ya que es mayor el porcentaje de concejales provenientes de otras provincias en el grupo de concejales rasos. Los datos obtenidos indican que los concejales sin cargos de responsabilidad en el seno del consistorio no pertenecían en la mayoría de los casos a la élite local que lo controlaba.

Nuestra conclusión es que dentro del Ayuntamiento de Bilbao había dos niveles, marcados por las tenencias de alcaldía, que coincidían siempre con la presidencia de las principales comisiones municipales. Una parte de los concejales no tenía apenas presencia en dichas comisiones, y en un régimen marcadamente jerárquico como el franquista el presidente de las mismas tenía mucho poder dentro de ellas, siendo necesaria su aprobación para tomar decisiones. Habría incluso un tercer nivel, el de los alcaldes, que serían quienes realmente controlaban el consistorio, aunque ellos mismos tenían que responder ante sus superiores políticos y justificar sus decisiones, sobre todo aquellas que tenían peso en el ámbito económico. Por lo tanto, dentro del Ayuntamiento los tenientes que presidían comisiones estaban por encima del resto de concejales, y aquellos estaban a su vez por debajo del alcalde ${ }^{22}$.

Estas diferencias se reflejan en el perfil socio económico de los tenientes y alcaldes. A pesar de que no son muy amplias, sí que resultan significativas. En caso de separar a estos en tres grupos, a los concejales por un lado, a los tenientes por otro y a los alcaldes por otro, las mencionadas diferencias serían mucho mayores, pero aun sin hacerlo muestran que existe una disparidad que supera el ámbito del consistorio. En definitiva, tal y como suponíamos, las personas que tenían puestos de mayor responsabilidad en las corporaciones, que verdaderamente tomaban las decisiones en las comisiones que luego el alcalde aprobaba, cumplían una serie de requisitos.

${ }^{21}$ Dicho análisis en la tesis doctoral del autor, Pérez Embeita, A., El poder local en el primer franquismo. Análisis prosopográfico de los miembros del Ayuntamiento de Bilbao y su gestión político-administrativa (1937-1959), UPV/EHU, 2019, pp. 173-201.

${ }^{22}$ Sería necesaria la realización de investigaciones en esta misma dirección en otros ayuntamientos del periodo, para comprobar así si esos dos niveles eran algo habitual en los consistorios franquistas. 


\section{Tabla 2}

Perfil laboral de los miembros del Ayuntamiento de Bilbao. 1937-1959

\begin{tabular}{lcccc}
\hline \multicolumn{1}{c}{ Profesión } & Alcaldes & $\begin{array}{c}\text { Tenientes que } \\
\text { presidieron comisiones }\end{array}$ & Concejales & $\begin{array}{c}\text { Datos } \\
\text { generales }\end{array}$ \\
\hline Empresario & $68 \%$ & $42 \%$ & $28 \%$ & $34 \%$ \\
Abogado & $16 \%$ & $25 \%$ & $21 \%$ & $22 \%$ \\
Profesionales liberales & $16 \%$ & $25 \%$ & $21 \%$ & $22 \%$ \\
Empleados por cuenta ajena & - & $8 \%$ & $30 \%$ & $22 \%$ \\
\hline
\end{tabular}

Fuente: elaboración propia.

Los tenientes de alcalde y los propios alcaldes del Ayuntamiento tenían una situación económica privilegiada en términos generales, habían cursado estudios superiores en la mayoría de los casos, poseían un alto nivel cultural y pertenecían a las clases más pudientes de la zona. Desde el punto de vista político no se aprecian grandes cambios entre este grupo y el grueso de concejales, aunque es importante remarcar que en total, la tradición política monárquica tenía más presencia en este grupo, y estaban representadas por algunos de los hombres más poderosos que pasaron por el consistorio. A pesar de ello, se mantuvo un equilibrio de fuerzas entre las familias políticas del franquismo, algo habitual en el funcionamiento de la dictadura.

Grosso modo, las características socio económicas de los miembros de las corporaciones municipales en el primer franquismo en Bilbao eran las siguientes: la media de edad de los concejales era de 44,6 años; eran originarios en su mayoría de la propia Bilbao, aunque la fuerte presencia de inmigrantes en la capital vizcaína hizo que también hubiera un porcentaje nada desdeñable de concejales provenientes de otras provincias; una mayoría de estos políticos tenía estudios superiores y una posición económica privilegiada, incluyendo la presencia de algunas de las más poderosas familias de la burguesía local, quedando así vinculado el poder político con el económico; y en el ámbito de la ideología, destaca el peso de un partido con una presencia social marginal como fue Renovación Española, cuya fuerza se explica debido a la pertenencia a dicha organización de algunos de los miembros de la burguesía local que apoyaron el fallido golpe de Estado y que constituían una parte importante de las élites loca- 
les ya antes de la llegada al poder de Franco. Los alcaldes de Bilbao tuvieron siempre orígenes carlistas o monárquicos vinculados a Renovación Española. También Falange tuvo una presencia destacada en el consistorio, pero sin puestos de tanta responsabilidad.

Con el paso del tiempo y al consolidarse la dictadura, las nuevas generaciones de políticos comenzaron a presentar unas características distintas en ese aspecto, debido a que no provenían de ninguna tradición política de las que habían apoyado al régimen y se podían considerar simple y llanamente franquistas, personas que habían realizado toda su carrera política con el franquismo en el poder. Una parte de estos políticos no solo diferían en el ámbito ideológico, sino que sus características socio económicas los situaban además fuera de la élite local que hemos descrito. Estas personas medraron políticamente a través de los engranajes del partido único y el Sindicato Vertical, y entraron a formar parte del consistorio mediante su inclusión como candidatos en el tercio sindical tras la puesta en marcha de la Ley de Bases del Régimen Local.

\section{La Ley de Bases del Régimen Local de 1945. Una (pseudo) nueva era}

El 17 de julio de 1945 entró en vigor la Ley de Bases del Régimen Local, que permitió la celebración de elecciones y cambió el sistema con el que la dictadura franquista escogía a los miembros de los Ayuntamientos en España. Tras la derrota del Eje en la Segunda Guerra Mundial, la débil posición internacional de la España de Franco llevó al régimen a realizar una serie de cambios de carácter cosmético con el fin de alejarse de las potencias derrotadas en la guerra y de asegurar su supervivencia en el tablero político internacional. Uno de esos cambios fue la celebración de elecciones municipales con el objetivo de presentarse como un país libre y democrático de cara al exterior. La realidad era que el franquismo controlaba las elecciones desde la designación de los candidatos, que el alcalde continuaba siendo elegido por el propio Gobierno ${ }^{23}$ y que toda la operación no fue otra cosa que una cuestión puramente estética. No obstante, la nueva ley trajo consigo cambios en el sistema por el que se escogía a los concejales, además de la renovación de una parte de los cuadros

${ }^{23}$ Los alcaldes eran nombrados por el Ministro de Gobernación en el caso de las capitales de provincia y las ciudades de más de diez mil habitantes, y por el Gobernador Civil en el resto de municipios. Ley del 17 de julio de 1945 de Bases de Régimen Local. 
políticos locales, que la dictadura procuró que fueran ocupados en buena medida por personas leales que habían hecho carrera en las instituciones de la dictadura, caso del Sindicato Vertical.

Con la entrada en vigor de la Ley de Bases de Bases del Régimen Local la representación municipal pasó a dividirse en tres grupos: el familiar, el sindical y el de entidades culturales, económicas y profesionales ${ }^{24}$. Estos denominados tercios eran considerados por el franquismo entidades naturales de las que extraer a las personas que llevaran a cabo la acción política del régimen en sus respectivos municipios. Cada tres años se renovaba a la mitad de los concejales de cada tercio, aunque en muchos casos los concejales simplemente cambiaban el tercio por el que resultaban elegidos, manteniéndose durante muchos años en el cargo ${ }^{25}$.

En el caso del tercio familiar, los requisitos para ser candidato eran: ser mayor de veintitrés años; saber leer y escribir; ser cabeza de familia y estar inscrito en el padrón. Es decir, además de la edad, la capacidad lectora y el empadronamiento, el único requisito era ser cabeza de familia, es decir, quién mantiene a la misma, de quien dependían los demás. Esto limitaba la elección a una persona por familia.

A la hora de proclamar a los candidatos la responsabilidad recaía sobre la Junta municipal del censo. Para ser incluido como candidato, los cabezas de familia debían haberlo solicitado antes, o haber sido propuestos. A la hora de proponer nombres, los concejales o exconcejales que llevaran al menos un año en el cargo tenían derecho a hacerlo; para otras personas era necesario cumplir una serie de requisitos. Así, se necesitaba el aval de dos procuradores o exprocuradores de las Cortes; de tres diputados o exdiputados provinciales y de cuatro concejales o exconcejales.

Los representantes del tercio sindical eran elegidos por los organismos sindicales del municipio. Para ello, la Junta local de elecciones sindicales ${ }^{26}$ asignaba a cada entidad el número de ediles que tenía que elegir en base a la importancia y cantidad de afiliados que tuviera. Los ediles se separaban en tres grupos: obreros, empresarios y técnicos. Cada vocal de la entidad elegía el número de concejales que le correspondía, separán-

${ }^{24}$ Ley del 17 de julio de 1945 de Bases de Régimen Local. Base 8. ${ }^{\text {a }}$ BOE, 18/07/1945, n. ${ }^{\circ} 199$, pp. 362-363.

${ }^{25}$ Sobre la legalidad municipal en el franquismo, ver: Martínez Marín, 1989, pp. 97-116.

${ }^{26}$ Esta Junta estaba integrada por: el delegado sindical local; el corresponsal de la obra de previsión social; un presidente de entidad local; un representante de los empresarios y otro de los trabajadores. 
dolos entre los económicos (los empresarios) y los sociales (los obreros y los técnicos). Los candidatos formaban siempre parte de los engranajes del partido único y eran personas con cargos de responsabilidad en los mismos, especialmente en el caso de los obreros y los técnicos.

Para poder ser candidato en este tercio, además de los requisitos que ya hemos mencionado, se exigía cumplir con al menos una condición de las siguientes: desempeñar o haber desempeñado un cargo electivo sindical; ser propuesto por escrito por dos procuradores sindicales de las Cortes, por acuerdo mayoritario de dos juntas de grupo o por un grupo de afiliados que represente al menos el veinte por ciento del total. Si no se alcanzaba el doble de puestos con las peticiones, es decir, si no había el doble de candidatos que de vacantes, la Junta elegía a los que faltaban ${ }^{27}$. Una vez más, nos encontramos con la necesidad de tener contactos para optar al cargo. De esta manera, la entrada en el consistorio de personas que no estuvieran bien relacionadas resultaba casi imposible. Por el contrario, las élites socio-económicas no tenían problema alguno para colocar a sus allegados en el Ayuntamiento, de tal manera que sin importar quién fuese finalmente elegido sus intereses se mantendrían a salvo y el poder local continuaría en sus manos.

Para el Tercio de Entidades, los concejales eran elegidos por los ya electos de los otros tercios. El único requisito que se sumaba a los genéricos que hemos mencionado al principio era el pertenecer a una entidad económica, cultural o profesional del municipio. La lista de la que se elegían era propuesta por el Gobernador Civil, lo que obligaba a tener una buena o al menos no tener una mala relación con quién ostentase el cargo. Huelga decir que la continuidad se facilitaba sin disimulo, a lo que hay que sumar la necesidad de contactos para desarrollar una carrera política. La cuestión central, por tanto, eran los apoyos que uno pudiera conseguir. Este tercio es quizás en el que más claramente queda representada la intención del gobierno. Su inclusión persigue únicamente un objetivo: que hubiera un tercio de concejales elegidos a dedo por el ejecutivo.

Estos cambios legales provocaron que el proceso de elección de los ediles se transformara por completo, aunque no hay que confundir el fondo con la forma, y las elecciones municipales del franquismo no fueron sino una operación de cirugía estética democrática sin ninguna consecuencia real sobre el control ejercido por el ejecutivo en todos los ám-

27 Martínez Marín, 1989, p. 115. 
bitos, incluida la designación de los concejales. Es decir, aunque hubiera alteraciones importantes sobre el papel, el franquismo continuó controlando de manera férrea quién accedía a estos cargos, y los propios requisitos que la ley planteaba para poder ser elegible impedían la entrada al consistorio de personas que no fueran afines a la dictadura y que no tuvieran las relaciones personales adecuadas.

\section{Un análisis del tercio sindical en el Ayuntamiento de Bilbao}

Recapitulando, la situación en el Ayuntamiento bilbaíno hasta la entrada en vigor de la Ley de Bases de Régimen Local y la celebración de las primeras elecciones en 1948 era la de una preeminencia absoluta de las élites locales, que arrojaba un perfil socio económico muy concreto y sin apenas variaciones, en el que destacaba la situación de privilegio que ostentaban sus miembros. La obligación de elegir a representantes del tercio sindical entre obreros y técnicos provocó un cambio en el ecosistema del consistorio, alterando el perfil de sus miembros, especialmente en lo relativo a los ámbitos académico, laboral y geográfico.

Consideramos que las razones tras la creación de este tercio y la aparición de la obligación de escoger a una parte de los políticos locales entre miembros de los organismos sindicales con la categoría de técnicos u obreros responde a la necesidad de renovar estos cargos intermedios, por un lado, y a la intención por parte de la dictadura de impulsar la entrada en política de personas que habían realizado una serie de méritos relacionados con su compromiso con las ideas del franquismo, por otro. Es decir, estas personas habían medrado a través de cargos en el seno del partido único y las instituciones dependientes del mismo, habían hecho carrera siempre en el contexto de la dictadura y le debían su posición al sistema, siendo ideológicamente exclusivamente franquistas. No provenían de las tradiciones ideológicas en las que se había apoyado el franquismo en sus inicios y de las que sí procedían la mayoría de los cargos políticos hasta ese momento. De esta manera, el régimen se aseguraba de que el cambio generacional se produjese dando el relevo a personas con unas características de su interés, que podemos resumir en el hecho de tener una absoluta lealtad hacia el sistema que les había permitido alcanzar estas cotas de poder.

Las primeras elecciones locales celebradas durante el franquismo se llevaron a cabo el 21 de noviembre de 1948, y el día 30 de dicho mes fueron verificados los hombres elegidos por el tercio sindical para formar parte del 
Ayuntamiento de Bilbao. En aquellas primeras elecciones siete ediles entraron a formar parte del consistorio mediante el tercio sindical, de las cuales cinco eran noveles y dos procedían de anteriores corporaciones. Como vemos, la mayoría de estas personas entraban por primera vez a la institución, sin haber tenido cargos políticos antes, lo que nos indica ya una diferencia con los otros tercios, en los que la mayoría de los ediles eran veteranos de anteriores mandatos. Así, en el tercio familiar tan solo dos de los siete concejales electos eran nuevos, situación inversa a la del tercio sindical, y en el tercio de entidades se da el mismo caso, con dos caras nuevas frente a cinco veteranos. Por lo tanto, la renovación de estos cargos se dio principalmente en el tercio sindical, frente a los otros tercios en los que fueron elegidos hombres que ya venían formando parte del Ayuntamiento, lo que señala una primera diferencia entre los tercios del sistema franquista.

Si nos detenemos en las características de los 17 ediles que fueron elegidos por el tercio sindical en las cuatro elecciones celebradas entre 1948 y 1959, estas arrojan el siguiente perfil para dichos hombres: La media de edad fue de 44,8 años. El concejal electo más joven de este tercio tenía 28 años al acceder al cargo, y el más veterano 67 . No eran, por lo tanto, personas jóvenes, sino que ya habían realizado méritos en el seno del partido único a lo largo de sus vidas. La mayoría tenían entre 35 y 45 años al resultar elegidos, es decir, eran hombres de mediana edad con cierta experiencia vital acumulada a sus espaldas, cuya lealtad había quedado probada tras años de servicio a la dictadura. En este caso, no hay diferencias remarcables entre estos concejales y los demás, ya que de hecho la media de edad del personal político bilbaíno durante el primer franquismo era muy similar.

En lo relativo al origen geográfico, 10 de los 16 concejales procedían de otras provincias, es decir, eran inmigrantes que se habían trasladado a Bilbao generalmente por motivos académicos o laborales. En algunos casos se trasladaron a la capital vizcaína siendo niños, acompañando a sus progenitores en el éxodo a la ciudad en busca de una vida mejor. Bilbao fue una ciudad que recibió una ingente cantidad de inmigrantes en diferentes oleadas desde la segunda mitad del siglo XIX, por lo que no resulta extraño encontrar a personas de diversos orígenes en el seno del Ayuntamiento ya antes de la aparición del sistema de tercios ${ }^{28}$. Además, en todos

${ }^{28}$ Hay algunos datos que nos ayudan a entender la magnitud de la cuestión de la inmigración en Bilbao, como el hecho de que entre 1860 y 1900 se triplicara la población de la ciudad, que para 1930 se había quintuplicado, pasando de las 62.417 habitantes de 1877 a los 304.364 de 1930. González Portilla, 2001, p. 33. 
los casos que hemos analizado estos hombres tenían arraigo en la ciudad en el momento de ser elegidos, y no hay un solo ejemplo de alguien que se trasladara a la villa vizcaína al haber sido escogido para el cargo. Así, un alto porcentaje de los habitantes de Bilbao procedía de otras provincias, especialmente de la zona de Castilla y León, lo que tuvo su reflejo en el origen de los ediles. De los 112 miembros de las corporaciones municipales bilbaínas entre 1937 y 1959 el 42 por ciento tenían un origen inmigrante; no obstante, en el caso de los elegido por el tercio sindical, este porcentaje aumenta hasta el 58 por ciento. Esta diferencia puede resultar significativa ya que en su mayoría, los inmigrantes llegados a Bilbao tenían una extracción social humilde, y se trasladaron a la ciudad en busca de mejorar su calidad de vida, lo que nos indica que no pertenecían a una élite privilegiada, algo que concuerda con la hipótesis de que la mayoría de los ediles elegidos por el tercio sindical no pertenecían dicha élite.

En lo referido al ámbito académico, existen diferencias importantes entre los datos obtenidos para los concejales del tercio sindical frente a los demás miembros de las corporaciones municipales. Sabemos que al menos un 67 por ciento de los ediles bilbaínos tenía estudios superiores, porcentaje que probablemente aumentaría al menos en cierta medida de lograr datos de todos los concejales. Habida cuenta de que la universidad era un espacio acotado para una pequeña parte de la sociedad, el que una mayoría de los miembros del consistorio bilbaíno hubiera cursado estudios en ella nos señala la pertenencia a una élite privilegiada de buena parte de los mismos. No obstante, esta situación cambia de manera radical si analizamos a los miembros del tercio sindical, de los cuales cuatro tenían estudios superiores sobre un total de dieciséis. Es decir, el 25 por ciento de estos concejales estuvo en la universidad, frente al 67 por ciento mencionado antes. Este dato implica ya una gran distancia entre el primer grupo y el segundo, y pone de manifiesto la situación de mayor privilegio de uno frente al otro, ya que una diferencia de más de cuarenta puntos en este campo deja claro que uno de los grupos era de carácter netamente elitista y el otro no.

El perfil laboral no hace sino confirmar esta impresión, con un alto porcentaje de ediles que desempeñaban trabajos reservados para la élite, en muchos casos dueños de negocios que pertenecían ya a sus familias y que implicaban una situación económica privilegiada, frente a unos ediles con unas características profesionales más comunes, cercanas a la ciudadanía y que desde luego proporcionaban a estos unos emolumentos mucho menores. En el Ayuntamiento de Bilbao la profesión más común era la de empresario (un 34 por ciento de los ediles se dedicó al mundo de la 
empresa), lo que engloba desde propietarios de negocios familiares a empresarios vinculados a algunas de las grandes compañías de la época, caso de los Bancos de Bilbao y de Vizcaya o de la Babcock \& Wilcox, verbigracia, incluyendo algunas personas que pertenecieron a los consejos de administración de múltiples empresas. La segunda profesión más habitual fue la de abogado (un 22 por ciento se dedicó a la abogacía, y fueron más los que estudiaron derecho aunque no se dedicaran profesionalmente a ello) debido en buena medida a la utilidad de esta carrera en el ámbito económico y empresarial. A una gran distancia de estas dos salidas profesionales se hallan todas las demás profesiones liberales, que unidas suman también un porcentaje del 22 por ciento, y entre las que encontramos ingenieros, arquitectos o médicos, entre otros. Y finalmente hallamos a los trabajadores por cuenta ajena, que suman así mismo otro 22 por ciento y que fueron los ediles que trabajaron como empleados para diversas empresas. A este último grupo pertenecen en su mayoría los concejales elegidos por el tercio sindical, algo lógico habida cuenta de su perfil académico, que hace que su perfil laboral sea el de trabajadores sin estudios superiores que desempeñaban trabajos de menor cualificación ${ }^{29}$.

Si desgranamos estos datos por época, es decir, si analizamos cada corporación municipal por separado, podremos comprobar como en los primeros consistorios constituidos en Bilbao no hubo empleados, e incluso en los primeros ejemplos de ediles clasificados como tales eran empleos de cierta cualificación, caso de un Agente de Cambio y Bolsa o un Perito Contable, por ejemplo. Es en 1941 cuando hallamos a un primer trabajador sin cualificación en el seno del Ayuntamiento, lo que arroja un porcentaje del 4 por ciento de empleados sobre el total de miembros; cifra que aumentó levemente en la siguiente corporación, llegando hasta el 8 por ciento, estadística que se dispara tras la celebración de las primeras elecciones municipales en 1948, cuando alcanza el 32 por ciento. Por lo tanto, la entrada de una mayor cantidad de hombres que no pertenecían a la élite local estuvo directamente vinculada a la aparición del sistema de tercios, y concretamente al tercio sindical, que como vamos a comprobar era el camino de entrada para buena parte de esos empleados al Ayuntamiento.

De los 17 hombres elegidos por el tercio sindical en Bilbao entre 1948 y 1959, cuatro fueron empresarios, tres técnicos y diez obreros u empleados.

${ }^{29}$ Hay que recordar que por el tercio sindical eran elegidos también empresarios que no compartían estas características y que de hecho sí pertenecían a esa élite local que controlaba la política y la economía de la zona. 
Este dato marca también una importante diferencia con el resto de ediles, ya que de hecho muestra una situación opuesta a lo visto en el los datos generales del Ayuntamiento bilbaíno. Así, entre los elegidos por este tercio son mayoría los empleados como un mecánico, un jefe de cocina o un obrero, frente a un empresariado minoritario. Los privilegiados son los menos, y se abre una brecha de gran tamaño entre el nivel de vida de estos ediles y el resto, miembros de la élite local. La mayoría de estos trabajadores sin cualificación no podrían haber llegado a formar parte del Ayuntamiento si el sistema franquista no hubiera creado las elecciones por tercios, incluyendo uno en el que se realizaban los méritos a través del partido único y que permitió a estas personas conseguir reunir los requisitos necesarios para llegar a obtener un puesto político de nivel intermedio como el de concejal. Además, hay un componente político en toda la cuestión, ya que en dicho tercio la importancia del Sindicato Vertical era capital y éste estaba controlado principalmente por FET y de las JONS, lo que indica una intención de impulsar la presencia del partido único en los Ayuntamientos. Así, se premiaba la lealtad y el trabajo a favor de la dictadura de estas personas, al tiempo que se otorgaba a Falange cierta cuota de poder en los consistorios.

Nos detendremos ahora en el aspecto ideológico. He mencionado antes el habitual equilibrio de fuerzas que el franquismo impulsó entre las diferentes tradiciones políticas que lo habían apoyado, forzando una cierta igualdad, teniendo en cuenta la idiosincrasia particular de cada zona. En el caso de Bilbao, destaca el peso de una fuerza con tradición en la provincia como fue el carlismo, así como la inusitada fuerza de un partido socialmente marginal como Renovación Española. Este último caso se explica debido a la militancia en dicha organización de una parte de la burguesía industrial que apoyó a la dictadura e incluso ayudó a financiar el fallido golpe de Estado, obteniendo después la recompensa por ello ${ }^{30}$. También

30 Sánchez Asiaín, 2012. En este estudio se da una gran cantidad de información sobre la financiación de ambos bandos, y en el caso franquista, aparecen reflejados los nombres de los más importantes contribuyentes que desde el primer momento dieron su dinero para la causa. Ese dinero fue recaudado por un comité presidido por el marqués de Arriluce de Ybarra, lo que ya nos indica que al menos parte de la alta burguesía vasca estaba implicada en la conspiración. Entre las personas que donaron dinero al bando franquista encontramos a José Luis de Oriol, la condesa Viuda de Zubiría, el conde de Aresti, Enrique Aresti y Torres, varios miembros de la familia Chávarri o el propio Fernando María de Ybarra y de la Revilla, marqués de Arriluce de Ybarra, pp. 67-68. José Luis de Oriol y Urigüen, padre del que más tarde sería alcalde de Bilbao José María de Oriol y Urquijo, ofreció a Mola su fortuna personal cuando el general buscaba financiación en Navarra, siendo uno de los 
Falange tuvo una importante presencia en el Ayuntamiento, auspiciada en este caso desde el poder, debido a la irrelevancia social que esta fuerza tenía en la provincia. Tuvieron además un papel marginal los procedentes de otros grupos monárquicos reaccionarios, caso de la Liga de Acción Monárquica o la Unión Patriótica. Y finalmente, el último grupo que hay que mencionar es el que hemos denominado Movimiento Nacional. Con el paso de los años y la consolidación del régimen, una nueva generación de políticos que habían desarrollado su carrera siempre en el contexto de la dictadura comenzó a formar parte de las instituciones. Estas personas no pertenecían a ninguna de las tradiciones ideológicas que habían apoyado al franquismo, y desde un punto de vista ideológico se pueden considerar solamente franquistas puros, hombres sin ninguna otra adscripción ideológica, leales únicamente a Franco y su régimen.

A lo largo de nuestra investigación hemos descubierto que, al darse la renovación de los cargos políticos del consistorio bilbaíno, una de las ideas subyacentes fue la de dar entrada a estos nuevos políticos puramente franquistas, e ir sustituyendo a las anteriores generaciones de ediles por hombres que fueran únicamente franquistas ${ }^{31}$. De esta manera, al ir formándose las sucesivas corporaciones municipales, se fue haciendo cada vez más numeroso el grupo de ediles únicamente franquistas, el Movimiento Nacional. No obstante, hay que recordar que existe un factor meramente biológico en esta cuestión, debido a que esta nueva generación no tenía edad para haber participado en la guerra civil o para haber tenido una carrera política previa al franquismo.

Durante el primer franquismo en Bilbao, cuatro fuerzas políticas o ideologías fueron las predominantes en el Ayuntamiento. Fueron Comunión Tradicionalista, Falange, Renovación Española y Movimiento Nacional. Entre ellas sumaban el 91 por ciento de los miembros del consisto-

más importantes aliados del franquismo en toda la zona, pp. 121-122. Las entidades bancarias, Banco de Bilbao, Banco de Vizcaya y Banco Urquijo, también tuvieron mucha importancia para el gobierno franquista en plena guerra, pp. 476-482. Sobre José Luis Oriol ver: Ugarte Tellería, 1998; De Pablo Contreras, 1996;

${ }^{31}$ Huelga decir que todos los miembros del Ayuntamiento fueron franquistas, aunque estuvieran más o menos de acuerdo con ciertas políticas de la dictadura. La diferencia estriba en que la gran mayoría de personas que apoyaron desde el inicio al dictador provenían de tradiciones políticas concretas, por lo que podían tener, en un momento dado, un conflicto de intereses a nivel moral entre sus lealtades políticas anteriores y su carácter franquista. Además, habían pertenecido a partidos con sus propias jerarquías y lealtades, mientras que los miembros del Movimiento Nacional solamente habían tenido vida política en el seno del propio franquismo. 
rio. Renovación Española con el 17 por ciento, Falange y Carlismo con el 22 por ciento, y el Movimiento Nacional con el 30 por ciento, fueron los grupos de la coalición reaccionaria que sustentó al franquismo que monopolizaron los puestos de la casa consistorial.

En lo relativo exclusivamente a los miembros del tercio sindical, el aspecto ideológico muestra así mismo divergencias con el resto de ediles. La preeminencia del Movimiento Nacional es mayor en este caso, ya que 9 de los 17 concejales están así clasificados. Es decir un 56 por ciento de estos hombres pertenecían a este grupo, los que supone un 26 por ciento más que entre el total de concejales. En cuanto al resto, encontramos a cuatro hombres de Falange, dos carlistas y uno procedente de la Liga de Acción Monárquica. Por tanto, los hombres elegidos a través del tercio sindical eran principalmente miembros leales de la dictadura. Al formar parte del Sindicato Vertical, es lógico que hubiera más miembros de Falange que de otras fuerzas, ya que como se ha mencionado antes se utilizó este tercio también para introducir a falangistas en la institución, y la presencia del carlismo, aunque pequeña, se explica debido al arraigo de dicha ideología en la zona y al equilibrio de poder impulsado desde las jerarquías del régimen. En cuanto al miembro de la Liga de Acción Monárquica, era un empresario de peso en el Bilbao de su tiempo, elegido a través de este tercio, pero miembro de la élite socio-económica que controló los resortes del poder en la capital vizcaína.

Uno de los méritos habituales entre los miembros del Ayuntamiento de Bilbao, mérito que solía ser una de las razones para que fueran escogidos para el cargo, era el papel jugado en la guerra civil. La guerra, como hecho fundacional del franquismo y símbolo de la lucha por la liberación del país, tuvo una importancia capital en la cosmovisión franquista, y la participación en el conflicto fue recompensada por el régimen de múltiples formas ${ }^{32}$. En el consistorio bilbaíno siempre hubo una representa-

32 Ejemplo de ello sería la reserva de puestos de trabajo públicos para excombatientes o excautivos del bando franquista. Otro claro ejemplo sería la creación y entrega de las Medallas de Hierro de la Villa de Bilbao por parte del Ayuntamiento. Estas medallas eran concedidas a: «los combatientes y a las madres o esposas de los caídos en las Unidades de la 1. ${ }^{\mathrm{a}}$ línea en el frente o de resultas de las heridas sufridas y que hubiesen nacido en Bilbao o hubiesen obtenido la vecindad; las madres o esposas de los asesinados en Bilbao en cárceles, barcos y en los extrarradios, o en los términos jurisdiccionales de la Villa; y las madres o esposas de los asesinados fuera del término de Bilbao, fuesen naturales de la Villa o vecinos de la misma». Fueron la condecoración más habitual entre los miembros del Ayuntamiento. Agirreazkuenaga y Urquijo Goitia, 2014, pp. 12-13. 
ción, más o menos numerosa, de veteranos de guerra o excautivos. Entre los elegidos por el tercio sindical, cuatro participaron de manera activa en la guerra civil, lo que no supone una gran diferencia con el total de concejales, y desde luego deja claro que los méritos bélicos no fueron la razón por la que estos hombres fueran elegidos, aunque en algunos casos la cuestión tuviera su peso. Además, de los cuatro hombres que participaron en el conflicto, dos fueron elegidos por el grupo de empresarios, eran miembros de la élite local y su papel en la guerra sería solamente un punto a favor más, pero no la razón principal para ser tenidos en cuenta como posibles concejales.

Finalmente, antes de centrarnos en las conclusiones, habría que analizar el papel jugado por los ediles del tercio sindical en el consistorio bilbaíno. Se ha explicado antes como en el Ayuntamiento había distintos niveles de poder, y como un grupo de ediles, formado por los alcaldes y los tenientes de alcalde que presidían además las comisiones municipales, era el que de facto controlaba la institución. La pregunta a responder sería si los miembros electos por el tercio sindical pertenecían a dicho o grupo o, por el contrario, eran miembros sin cargos de responsabilidad en las corporaciones municipales. La respuesta es que solamente dos de los diecisiete hombres aquí analizados llegaron a tener cargos de cierto peso en el consistorio, uno de ellos como presidente de la Comisión de Cultura y el otro llegando incluso a ocupar el puesto de alcalde como interino tras el cese en 1959 de Joaquín Zuazagoitia. Sin embargo, los quince miembros restantes de este grupo no tuvieron apenas peso en las corporaciones, y aunque hasta 8 de ellos llegaron a ocupar tenencias de la alcaldía fueron las menos importantes y no presidieron comisión alguna, siendo la quinta tenencia el grado más alto que hemos encontrado. Por lo tanto, el papel de estas personas fue más bien testimonial en la gran mayoría de los casos.

En cuanto a los dos hombres que sí tuvieron cargos de responsabilidad, hallamos por un lado a un empresario falangista, (José María Maiz Zulueta, «camisa vieja» de Falange) fundador del partido en Vizcaya y con cargos importantes en el mismo, vinculado a los grandes nombres de la burguesía industrial. Es decir, alguien que a pesar de entrar en el consistorio por el tercio sindical era miembro de la élite local. Y por otro a un hombre proveniente de un pueblo de La Rioja que emigró a Bilbao para estudiar en la Universidad de Deusto, aunque no acabó la carrera, (José María Espinosa Elías) y que realizó toda su carrera política en el seno de las instituciones franquistas, con cargos en el partido único que le permitieron medrar políticamente. En este segundo caso si tenemos un ejemplo 
del perfil mayoritario entre estos ediles, que a diferencia de J. M. Maiz Zulueta, no pertenecían a la élite local e hicieron carrera en la política mediante otros caminos, a través del partido único.

Resumiendo, las características de los ediles elegidos a través del tercio sindical serían las siguientes: Eran hombres de mediana edad, entre los 40 y los 50 años en su mayoría; un 58 por ciento procedía de fuera de Vizcaya, sobre todo de Castilla y León; un 25 por ciento tenía estudios superiores y trabajos cualificados o bien eran empresarios, frente al 75 por ciento de trabajadores sin cualificación; en el ámbito ideológico eran más los que no provenían de ninguna de las tradiciones políticas que habían apoyado a la dictadura, es decir, eran franquistas puros que desarrollaron su vida política ya con el franquismo presente; su participación en la guerra civil no resulta destacable, ya que solo unos pocos tomaron parte en el conflicto; y, finalmente, no tuvieron cargos de responsabilidad en el seno de las corporaciones municipales además de las dos excepciones que hemos explicado.

\section{Conclusiones}

En definitiva, los concejales elegidos por el tercio sindical no compartían las mismas características con la mayoría de los miembros del Ayuntamiento, y sobre todo no formaban parte de la élite que controló no solo los resortes de poder sino también los medios de producción a nivel local. Fueron hombres con trabajos sin cualificación o al menos sin estudios superiores, que hicieron carrera a través del partido único ya con la dictadura en el poder y que lograron medrar políticamente hasta convertirse en el relevo generacional de los políticos de nivel intermedio en instituciones como el Ayuntamiento de Bilbao.

¿Por qué la dictadura franquista decidió introducir a estas personas en el consistorio bilbaíno? La institución continuó estando controlada por las élites locales, que mantuvieron además los puestos de responsabilidad en el Ayuntamiento, pero el régimen impulsó la entrada de este nuevo perfil político. Las razones subyacentes tras esta decisión, que en la práctica no varió el funcionamiento de la institución ni el equilibrio de poder de manera sustancial, estarían en la pretensión del franquismo de crear una nueva generación de políticos que debieran toda su carrera al régimen, que no tuvieran lealtades compartidas con sus antiguos partidos políticos y cuyo apoyo a la figura del dictador no tuviera ningún tipo de fisura. Una vez consolidada a nivel interno, la dictadura aprovechó la operación esté- 
tica que supusieron las elecciones locales para introducir a esta nueva generación de políticos forjados en su seno.

Por lo tanto, la introducción del tercio sindical y la obligación de elegir a representantes del mismo entre obreros y técnicos respondió a una estrategia política cuyo objetivo era introducir a personas que no pertenecían a los círculos de poder de las élites en las instituciones locales, ya que la dictadura se había servido de esas «fuerzas vivas» para obtener el control de cada localidad, pero una vez consolidada, quiso tener en las casas consistoriales a hombres de total confianza, moldeados políticamente durante el franquismo y leales únicamente al dictador que les había permitido alcanzar esas posiciones de poder. Sería necesario comprobar si esta situación se repite en otras localidades durante el mismo periodo, para corroborar esta estrategia por parte de la dictadura, o, por el contrario, para considerar el caso de Bilbao no como la norma sino como la excepción en lo que se refiere a la renovación de estos cuadros políticos intermedios y al plan seguido para ello por parte de la dictadura.

\section{Bibliografía}

AgirReazkuenaga, Joseba y UrquiJo Goitia, Mikel, Bilbao desde sus alcaldes Vol. III (1937-1979), Ayuntamiento de Bilbao, Bilbao, 2008.

AgirReazkuenaga, Joseba y Alonso Olea, Eduardo, Historia de la Diputación Foral de Bizkaia. 1500-2014, Diputación Foral de Bizkaia, Bilbao, 2014.

AgirReaZkuenaga, Joseba y URQuijo Goitia, Mikel, Informe sobre la concesión de honores por el Ayuntamiento de Bilbao en el periodo 1875-2014, UPV/EHU, 2014.

AizPuru Murua, Mikel, Barakaldo. Una ciudad industrial. Esplendor crisis y renovación (1937-2004), Ediciones Beta, Bilbao, 2010.

AizPuru Murua, Mikel (dir.), El otoño de 1936 en Gipuzkoa: los fusilamientos de Hernani, Alberdania, Irun, 2017.

ALCALDE, Ángel, Los excombatientes franquistas (1936-1965), Prensas Universitarias de Zaragoza, Zaragoza, 2014.

Arco Blanco, Miguel Ángel, El primer franquismo en Andalucía Oriental (1936-1951). Poderes locales, instauración y consolidación del régimen franquista, Universidad de Granada, Granada, 2005.

ARRIETA, Leire, Diputación y modernización. Gipuzkoa, 1940-1975, Diputación Foral de Gipuzkoa, San Sebastián, 2003.

BARRUSO BARÉs, Pedro, «Poder político y representación social en Andoain durante el primer franquismo (1936-1951)», en Leycaur, n. ${ }^{\circ}$ 6, Andoain, 2000, pp. 255-350. 
BARRUSO BARÉs, Pedro, Violencia política y represión en Gipuzkoa durante la guerra civil y el primer franquismo (1936-1945), Hiria, San Sebastián, 2005.

CABrero, Claudia, Mujeres contra el franquismo (Asturias 1937-1952). Vida cotidiana, represión y resistencia, KRK, Oviedo, 2006.

CAnales SERrano, Antonio Francisco, Las otras derechas: derechas y poder local en el País Vasco y Cataluña en el siglo XX, Marcial Pons, Madrid, 2006.

Canales Serrano, Antonio Francisco, «Las lógicas de la victoria. Modelos de funcionamiento político local bajo el primer franquismo», en Historia Social, n. ${ }^{\circ}$ 56, 2006, pp. 111-130.

Cenarro Lagunas, Ángela, Cruzados y camisas azules: los orígenes del franquismo en Aragón 1936-1945, Prensas Universitarias de Zaragoza, Zaragoza, 1997.

Clara, Josep, El personal politic de l'Ajuntament de Girona (1917-1987), Cercle d'Estudis Històrics i Socials, Girona, 1987.

Cobo Romero, Francisco, La guerra civil y la represión franquista en la provincia de Jaén (1936-1950), Instituto de Estudios Jienenses, Jaén, 1994.

De Pablo Contreras, Santiago, «Las empresas periodísticas de José Luis Oriol Heraldo Alavés y Pensamiento Alavés», en La prensa de los siglos XIX y XX metodología, ideología e información. Aspectos econòmicos y tecnológicos: I Encuentro de Historia de la Prensa, coord. por Carmelo Garitaonandia Garnacho, Manuel Tuñón de Lara, 1996.

DOMPER LASÚS, Carlos, «El franquismo a través de las urnas. Metodología, fuentes y retos para una aproximación electoral al régimen de Franco», en Política y Sociedad, vol. 55, n. ${ }^{\circ}$ 1, 2018, pp. 115-134.

FERRARI, Marcela, «Prosopografía e historia política. Algunas aproximaciones», en Antíteses, vol. 3, n. . 5, 2010, 529-550.

GARCÍA RAMOS, Domingo, Instituciones y vida política durante la guerra civil y el franquismo. Palencia (1936-1975) (tesis doctoral), UNED, Madrid, 2003.

GonzÁlez Cortes, José Ramón y Aguado Benítez, Raúl, Extremadura durante el primer franquismo (1939-1959), Diputación de Badajoz, Badajoz, 2010.

GonZÁlez PoRTILla, Manuel, Los orígenes de una metrópoli industrial: la Ría de Bilbao. Vol.1. Modernización y mestizaje de la ciudad industrial, Fundación BBVA, Bilbao, 2001.

Hernández Burgos, Claudio, «La dictadura en los rincones: la historiografía del franquismo y la perspectiva local», en Historia Actual, n. ${ }^{\circ}$ 36, 2015 , pp. 69-82.

Larraza Micheltorena, María del Mar, De leal a disidente: Pamplona, 19361977, Ediciones Eunate, Pamplona, 2003.

Larraza Micheltorena, María del Mar, El Ayuntamiento de Pamplona desde sus hombres, 1940-1979: biografía colectiva y gestión municipal, Eunate, Pamplona, 2012. 
LóPEZ DE MATURANA, Virginia, La reinvención de una ciudad: poder y política simbólica en Vitoria durante el franquismo (1936-1975), UPV/EHU, Bilbao, 2014.

MARín Corbera, Martí, Els ajuntaments franquistes a Catalunya. Política i administració municipal, 1938-1979, Pagés Editors, Lleida, 2000.

Marín Corbera, Martí; Risques, Manel, TÉBAR, Javier y CASAnEllas, Pau, Gobernadores. Barcelona en la España franquista (1939-1977), Comares, Granada, 2015.

Martínez Marín, Antonio, La representatividad municipal española. Historia legislativa y régimen vigente, Universidad de Murcia, Murcia, 1989.

Molinero, Carme, Catalunya durant el franquisme, Empuries, Barcelona 2009.

NiCOLÁs MARín, Encarnación, Instituciones murcianas en el franquismo (19391962). Contribución al conocimiento de la ideología dominante, Editora Regional, Murcia, 1982.

Nicolás Marín, Encarnación, «Los poderes locales y la consolidación de la dictadura franquista», en Ayer, n. ${ }^{\circ}$ 33, 1999, pp. 65-85.

Ponce Alberca, Julio, «Los gobernadores civiles en el primer franquismo», en Hispania: Revista Española de Historia, vol. 76, n. ${ }^{\circ}$ 252, 2016, pp. 245-272.

Presas Sobrado, Adrián, «La dictadura desde la base: un análisis del poder local en la España del primer franquismo desde una perspectiva comparada», en GonzÁlez Madrid, Damián; Ortiz Heras, Manuel; PÉrez Garzón, Juan Sisinio (coords.), La Historia, lost in translation?, Asociación de Historia Contemporánea, Albacete, 2016.

RoDRÍGUEZ BARREIRA, Óscar, Miserias del poder : los poderes locales y el nuevo Estado franquista 1936-1951, Universidad de Valencia, Valencia, 2013.

SÁNCHEZ AsiAín, José Ángel, La financiación de la guerra civil española. Una aproximación histórica, Editorial Planeta, Barcelona, 2012.

SAnz Alberola, Daniel, La implantación del franquismo en Alicante. El papel del Gobierno Civil (1939-1946), Publicaciones de la Universidad de Alicante, Alicante, 1999.

SANZ HoYA, Julián, La construcción de la dictadura franquista en Cantabria, Universidad de Cantabria, Santander, 2008.

Stone, Lawrence, El pasado y el presente, Fondo de Cultura Económica, México, 1986.

UGARTE, Javier, La nueva Covadonga insurgente: orígenes sociales y culturales de la sublevación de 1936 en Navarra y el País Vasco, Biblioteca Nueva, Madrid 1998.

URQUIJO, Mikel, «"Las buenas familias de Bilbao": espacios de sociabilidad y control del poder (Bilbao, 1880-1979)», en NovArESE, Daniela, Sociabilitá. Rituali, pratiche, spazi, modelli dello stare insieme. Esperienze italiane e europeen fra etá moderna e contamporánea, Aracne editrice, Roma, 2019, pp. 257-281. 


\section{Financiación}

Este trabajo forma parte de la actividad del Grupo de investigación consolidado del Sistema Universitario Vasco, (ref. IT 1263-19) y del Proyecto «Biografía colectiva y análisis prosopográfico más allá del Parlamento» (ref. PGC2018-095712-B-100), financiado por Ministerio de Ciencia, Innovación y Universidades.

\section{Datos del autor}

Antonio Pérez Enbeita (Bilbao, 1991), doctor en Historia Contemporánea por la Universidad del País Vasco. Ha publicado en 2019 su tesis doctoral dirigida por Mikel Urquijo Goitia y titulada «El poder local en el primer franquismo. Análisis prosopográfico de los miembros del Ayuntamiento de Bilbao y su gestión político-administrativa (1937-1959)». Ha colaborado en la investigación sobre los bombardeos en núcleos urbanos del País Vasco durante la guerra civil española, en la enciclopedia online "Bilbaopedia» y ha realizado una investigación para el Ayuntamiento de Bilbao sobre la beneficencia en el siglo XIX a través de la figura de Casilda de Iturrizar. En la actualidad es investigador contratado en Gogora, Instituto de la Memoria, la Convivencia y los Derechos Humanos. 